\title{
Mapping system for tractor-implement performance
}

\begin{abstract}
novel data acquisition and differential global positioning system has been successfully integrated on-board a Massey Ferguson 3060 agricultural tractor for mapping tractorimplement performance with its geographical location. Both commercial and specially developed transducers were incorporated into the system for the needed tractor-implement performance measurements. Transducers were developed to measure drawbar pull at the tractor drawbar point, wheel torques and theoretical speeds at both tractor rear drive wheels, PTO torque at the tractor PTO output, forces at the tractor three-point linkages, and tillage depth at the tractor rockshaft. This complete and integrated system is capable of measuring, displaying and recording in real-time among others, tractor's theoretical travel speed, actual travel speed, fuel consumption rate, rear drive wheel slippage, rear drive wheel torque, pitch and row angles, and also implement's PTO torque, drawbar force, three-point hitch forces, and tillage depth. With the added differential Global Position System (DGPS) option, the system could be used for spatial mapping of the tractor-implement field performances. Under such configuration, the complete system is capable of measuring, displaying, and recording in real-time tractor-implement's geo-position in the field with respect to its measured performance. Static calibration tests on various associated transducers for the required measurements showed excellent linearity with correlation coefficients that are closed to 1 . The developed system has been extensively and successfully field demonstrated for spatial mapping of tractor-implement field performance with a mounted disk plow on Serdang Series sandy clay loam soil.
\end{abstract}

Keyword: Precision farming; Data acquisition system; Mapping system; Transducers; Tractor-implement performance 